\title{
Testosterona, de Sabina Berman: revés y continuidad de la comedia romántica
}

\author{
Testosterona by Sabina Berman: setback and continuity \\ of romantic comedy
}

Claudia Gidi

ORCID: 0000-0002-8581-0963

Universidad Veracruzana, México

cgidi65@hotmail.com

Resumen:

En este artículo me ocupo de una de las obras teatrales más recientes y exitosas de Sabina Berman: Testosterona. En ella, la autora centra la mirada en las conflictivas relaciones de poder entre hombres y mujeres, apelando a la comedia romántica; género dramático y cinematográfico que suele tratar, desde una perspectiva humorística, las relaciones amorosas y del enfrentamiento entre los sexos. Considero que es importante analizar cómo Berman aprovecha muchas de las características artísticas de dicho género para darles un giro y poner en evidencia los mecanismos sociales que avasallan a las mujeres; con lo que trastoca todo un horizonte de expectativas.

Palabras clave:

comedia romántica, teatro mexicano, relaciones de género, Sabina Berman.

Abstract:

In this article I deal with one of Sabina Berman's most recent and successful plays: Testosterone. In it, the author focuses her 
gaze on the conflicting power relations between men and women, appealing to romantic comedy; a dramatic and cinematographic genre that usually deals, from a humorous perspective, with love relationships and confrontation between the sexes. I consider that it is important to analyze how Berman takes advantage of many of the artistic characteristics of this genre to turn them around and highlight the social mechanisms that overwhelm women; thus, upsetting a whole horizon of expectations.

Key words:

romantic comedy, Mexican theater, gender relations, Sabina Berman.

DOI: https://doi.org/10.36798/critlit.vi21.349

Recibido: 13 de junio de 2020

Aceptado: 27 de septiembre de 2020

La desigualdad en las relaciones entre hombres y mujeres es un problema social extendido y de larga data que rebasa con mucho las fronteras de las naciones. Sin embargo, es innegable que, en México, el machismo, una de las formas que adopta la desigualdad entre los sexos, constituye un escollo social de gran trascendencia. Por si fuera poco, la sociedad mexicana actual se encuentra atrapada, desde hace más de una década, en un ciclo de violencia del que por desgracia no hemos logrado salir. En ese contexto, la violencia contra las mujeres ha llegado a límites pavorosos.

Ante esta situación, es normal que el arte no mire hacia otro lado, ni pase por alto la crisis en la que estamos inmersos; crisis que sin duda plantea preguntas acuciantes. En el ámbito teatral, Sabina Berman, sin duda una de las dramaturgas más importantes del México contemporáneo, ha indagado sobre diversos asuntos centrales de la vida actual en el país; y cuenta en su trayectoria con una serie de obras donde se ocupa, precisamente, del problema de las relaciones de género. Muestras de este interés fundamental son: Aguila 
o sol, El bigote, ${ }^{1}$ Entre Villa y una mujer desnuda y Muerte súbita. Es importante hacer notar también que, a pesar de que la autora considera como un asunto grave y de gran trascendencia social tanto el problema de género como el machismo asociado a él, el tratamiento artístico que con frecuencia le confiere se acerca a las estéticas de la risa, ya sea apelando al más incisivo humor negro o al sarcasmo. ${ }^{2}$

En esta ocasión me interesa enfocar la mirada en Testosterona, una de las obras dramáticas más recientes de Berman, publicada por El Milagro en 2013 y llevada a las tablas con gran éxito en más de una ocasión; a la fecha ha tenido cuatro temporadas en la Ciudad de México y se ha representado también en diversas ciudades del extranjero, como Madrid, Lima, Santiago de Chile y Buenos Aires -donde la puesta en escena tuvo tal éxito, que se mantuvo en cartelera por tres años, con el teatro lleno-_. ${ }^{3}$ Me interesa estudiar este texto no sólo porque en él la autora actualiza el debate que gira alrededor de la violencia y el sojuzgamiento de la mujer —el cual puede adoptar desde formas sutiles, muchas veces naturalizadas por las mismas mujeres, hasta las más agresivas y evidentes_-, sino porque lo hace centrándose en personajes pertenecientes a una clase social media-alta ilustrada, y apelando, paradójicamente, a un género dramático y cinematográfico que en principio no podría parecer más alejado de la problemática que trata: la comedia romántica; géne-

${ }^{1}$ El bigote es una de las obras en un acto que integran El suplicio del placer. Sin embargo, como es habitual en Berman, existe más de una versión de este texto dramático: en 1977, El suplicio... estaba integrado por tres obras, mientras que en 1998 aparece formado por cuatro. Con todo, en una edición posterior del Fondo de Cultura Económica — Puro Teatro (2004)—, en la que Berman reúne once de sus textos dramáticos, El suplicio... vuelve a aparecer integrado únicamente por tres piezas.

${ }^{2}$ En una entrevista con Francine A’ness, Berman ha dicho: "para mí el machismo no es una fuerza ridícula, es una fuerza muy amenazante que conduce a mucho dolor. Se le puede ver el lado ridículo, pero es una fuerza real, muy viva” (56)

${ }^{3}$ Para este ensayo uso la edición de El Milagro, de 2013, aunque existe una versión posterior, que continúa inédita (de 2017), que amablemente me proporcionó la autora. 
ro que convencionalmente trata de relaciones amorosas, desde un punto de vista humorístico.

Como en muchas tragedias de corte neoclásico, la obra de Berman se desarrolla en un solo espacio, en un lapso de 24 horas; tiempo en el cual los personajes sufren un vuelco de fortuna. Sin embargo, según se nos advierte en una de las primeras acotaciones, no estamos frente al género del drama considerado históricamente como el más noble y elevado; lo cual no supone, como veremos, que los acontecimientos recreados sean poco trascendentes. Por el contrario, en dicha acotación se lee que se trata de una "comedia romántica"; aunque a renglón seguido se nos explique que Miky, su protagonista, no se ajusta al estereotipo femenino de este género dramático.

Con esta información, al comenzar la obra, el lector convencional se prepararía para disfrutar de una pieza en la que, pese a las múltiples peripecias que puedan sufrir sus personajes principales, culminará con un desenlace feliz, en el que el amor saldrá airoso. Desde luego, no me parece ingenuo ni intrascendente que se clasifique la obra en un género literario y cinematográfico específico, dado que los géneros no solo traen consigo una historia y un desarrollo estético particulares, sino que cada uno de ellos entraña también una cierta visión de mundo. Sin embargo, como intentaré mostrar, Sabina Berman le da un giro de tuerca en muchos aspectos a esta forma de comedia — en nuestros tiempos, mucho más presente en el cine que en el teatro- Por esta razón, me interesa reflexionar sobre la manera en que Berman trastoca el género y, con ello, todo un horizonte de expectativas.

Así pues, tras una primera lectura surgen algunas preguntas que considero vale la pena intentar responder: ¿en qué medida se puede pensar que Testosterona es una comedia romántica? Y si lo es, ¿cuáles de sus rasgos característicos permanecen y cuáles se transforman? $\mathrm{Y}$ finalmente, ¿qué sentidos se generan a partir de estos cambios y en virtud de su peculiar configuración artística? Para pensar con atención en estos problemas, es preciso tener presentes los rasgos con los que nació la comedia romántica en el teatro, para observar después cómo, desde la primera mitad del siglo xx y hasta la 
actualidad, este género adquirió carta de naturalización en el cine hollywoodense y, con ello, todo un conjunto de rasgos claramente diferenciados. Asimismo, considero que, si bien nuestro concepto del amor ha sido forjado por múltiples discursos sociales, en la actualidad el cine ha cobrado una importancia especial, que le ha permitido incidir en el imaginario de millones de personas. En otras palabras, hoy día el cine constituye un referente cultural tan importante que difícilmente podría pasarse por alto.

Para emprender nuestra aproximación a un género tan elusivo como puede resultar la comedia, me parece oportuno comenzar recordando los planteamientos de Northrop Frye en Anatomía de la crítica, a propósito del mythos de primavera. ${ }^{4}$ Para Frye, las obras literarias que participan de este mythos se vinculan con una tradición teatral que comienza de manera destacada con Plauto y Terencio - aunque ciertamente existen antecedentes en Aristófanes- y que, desde luego, se extiende hasta la actualidad. El investigador señala que, en términos generales, en el argumento cómico se recrea el paso de una forma de sociedad a otra, que el público reconoce como conveniente y dichosa - aunque con frecuencia resulte más deseable que verosímil- Es el paso de un estado de conflicto a otro de armonía; el recorrido de las cosas tal como son hasta llegar a la forma en que deben ser. Entraña, por lo tanto, un desenlace feliz, acompañado de un descubrimiento imprevisto y comúnmente precedido por una serie de sucesos también inesperados. Siguiendo esta línea de pensamiento, es posible afirmar que la comedia aspira al bien común, que triunfa sobre un modelo social caduco y a menudo represivo, ya sea porque se castigue un vicio o porque los amantes, jóvenes por lo general, logran superar los obstáculos que se les plantean, hasta que su amor cristaliza en una boda.

Si la Comedia Antigua tenía un carácter eminentemente político y satírico, la Comedia Nueva — con los latinos a la cabeza y luego

${ }^{4}$ Frye considera que existen cuatro categorías, más amplias que los géneros literarios ordinarios y anteriores a ellos: la romántica, la trágica, la cómica y la irónica o satírica. 
sus herederos renacentistas- desarrolla con frecuencia una intriga amorosa: un muchacho y una muchacha deben superar obstáculos, como los que pueden surgir del desacuerdo del padre (senex). Sin embargo, es frecuente también que el héroe deba resolver otro tipo de dificultades, como su pertenencia a una clase social inferior, la falta de recursos económicos o el deseo de algún rival. Como hemos dicho, la historia concluye, por regla general, con la cristalización de una nueva sociedad, que gira alrededor de la pareja de los jóvenes amantes, y no es raro que el feliz desenlace se celebre con una fiesta.

A propósito de la comedia romántica, que es la variante que ahora interesa, Frye considera que también hunde sus raíces en "la tradición medieval del drama ritual de las estaciones", al que también llama "el drama del mundo verde". Es decir, del "triunfo de la vida y el amor sobre la tierra baldía”, del ciclo vital que le permite a la naturaleza renacer una y otra vez (241). Así pues, en la comedia romántica — según se desarrolla en el teatro isabelino, con Shakespeare a la cabeza-, la trama comienza en el mundo "normal", el de la vida cotidiana, para trasladarse después a un "mundo verde", en el que se resuelven los conflictos cómicos, para finalmente regresar al sitio de partida. Este "mundo verde" se puede asociar de manera inmediata con el bosque, pero simboliza algo más: representa no solo la naturaleza idílica, el locus amoenus de la inocencia, sino la fecundidad, el triunfo de la primavera sobre el invierno e incluso el mundo onírico en el que se realizan nuestros deseos.

Siguiendo la misma línea de pensamiento, observamos que el amor cortés, tal como se desarrolló en la literatura medieval, ha dejado también una importante huella en la comedia romántica. Se trata de un amor idealizado, que no llega a la consumación sexual, y en el que se destacan las hazañas y servicios que ofrece el caballero a su dama. Sin embargo, con el desarrollo del género cómico, los personajes femeninos se alejan de la dama muda y distante del amor cortés, pasiva receptora del amor, para desarrollarse como caracteres con una participación determinante en el desarrollo de la trama, así como en la solución de los problemas y la restauración del bien común (Carbajosa 360). Tampoco es extraño que en este tipo de 
comedia campee cierta dosis de melancolía, lo que en ocasiones ha llegado al punto de poner en entredicho su afiliación al género cómico, según se entendía en la Antigüedad.

El enfrentamiento entre los sexos constituye uno de los conflictos que muy a menudo deben superar los protagonistas cómicos de la vertiente romántica. Dicho enfrentamiento sirve como motor de la acción —y es común que se desarrolle en ambientes lujosos o fantásticos, donde personajes extravagantes generan sucesos igualmente extravagantes-. Entre sus características cobran también relieve los diálogos ingeniosos, el ritmo ágil (si no francamente vertiginoso), el tono ligero y los enredos cómicos, a menudo asociados con los cambios de identidad. Un ejemplo teatral paradigmático es sin duda Sueño de una noche de verano, de William Shakespeare; obra que Irving Singer, en su amplio estudio histórico sobre el amor, considera que ha servido como referencia obligada para las comedias románticas cinematográficas de principios del siglo xx. ${ }^{5}$ Así pues, desde sus orígenes esta comedia ha constituido el espacio idóneo para elaborar discursos artísticos sobre lo masculino y lo femenino, así como en lo que toca a las relaciones amorosas.

La edad de oro de la comedia romántica cinematográfica o screwball comedy (comedia "alocada", "disparatada" o "de enredo") se da entre los años treinta y cuarenta del siglo xx. En ella prevalece un notable optimismo, ya que se percibe una gran confianza en la capacidad de regeneración de los individuos. Pablo Echart afirma que: "Frecuentemente bajo la apariencia del enfrentamiento y del rechazo, subyace un afán lúdico, animoso, y una alta sensación de complementariedad, que, no obstante, tiene que redefinirse o

${ }^{5}$ En opinión del investigador, la pareja conformada por Titania y Oberón "es el arquetipo de las comedias hollywoodescas de enredos de la década de 1930, en las que unos divorciados se juegan malas pasadas, experimentan con compañeros extramaritales que resultan tan inadecuados como un burro para la Reina de las Hadas, y terminan por darse cuenta de que, aunque su amor es imperfecto, resulta preferible (por alguna razón desconocida) a cualquiera de las alternativas" (268). 
encontrarse" (La comedia 52). Así, los que están hechos el uno para el otro se descubren, o se reconcilian y renuevan su relación matrimonial. ${ }^{6}$

Si se compara dicha expresión cinematográfica con la imagen victoriana de la mujer de un par de décadas antes, se advertirá que hay en los años 30 y 40 una leve tendencia a reivindicar a la mujer; sin embargo, casi todas sus protagonistas, aun las independientes y plenamente incorporadas al mundo laboral, aspiran a encontrar al hombre ideal y casarse. Es decir que, por más inteligentes, trabajadoras y bellas que sean, no parecen realizarse plenamente si no tienen junto a ellas a un hombre que las ayude a ver sus propias virtudes. En otras palabras, se confirman, una y otra vez, "las diferencias jerárquicas entre los roles desempeñados por hombres y mujeres"; por lo que se puede considerar que el género ha sido "un instrumento más de la subordinación de estas últimas en la sociedad patriarcal" (Deleyto, "Introducción" 117).

Con todo, como sus antecedentes teatrales isabelinos, las mujeres protagonistas de la comedia hollywoodense de la época se caracterizan por ser inteligentes, ingeniosas y capaces de esgrimir diálogos tan agudos como lúdicos. Sin embargo, el lugar donde ocurren los sucesos — alejados de las leyes que rigen la vida cotidiana y que permite soluciones idealizadas de los conflictos- deja de ser el espacio pastoral de la comedia romántica del siglo Xvi. Donde ocurren los sucesos representados por la nueva comedia de principios del siglo xx suelen ser los lugares de retiro de la burguesía, ${ }^{7}$ aunque con el paso del tiempo acabará por imponerse el entorno citadino. Un ejemplo notable de esta transformación es Manhattan (1979), de Woody Allen, filme que se desarrolla en la Gran Manzana, con su aura de magia y cosmopolitismo.

${ }^{6}$ Son buenos ejemplos de este tipo de filmes: Al servicio de las damas (My Man Godfrey) de Gregory La Cava y La pareja invisible (Topper) de Norman Z. McLeod. Ambas de la década de los treinta.

${ }^{7}$ Así ocurre en películas como La pícara puritana, La fiera de mi niña, La costilla de Adán y Las tres noches de Eva (Echart, La comedia 54-55) 
El tono desenfadado y festivo es otra de sus constantes, ya que se relaciona estrechamente con la manera optimista de concebir el mundo, es decir, la confianza en el efecto benéfico del amor y la capacidad de los seres humanos de aprender de sus errores. Son comedias que ponen el énfasis en la reconciliación y el reconocimiento, que se da cerca del desenlace; aunque se trate de un final más deseable que realista. Sin embargo, Celestino Deleyto hace algunas precisiones al respecto que vale la pena considerar. Si bien es cierto que la comedia romántica ha promovido el matrimonio y la familia nuclear como base de la organización social, por lo que ha proclamado "la heterosexualidad, la monogamia y el amor romántico como la opción más deseable en las relaciones humanas, en detrimento de una serie de alternativas tradicionalmente reprimidas", con los cambios sociales suscitados hacia los años sesenta del siglo pasado - "la crisis de la pareja, la proliferación de las opciones sexuales, la decreciente credibilidad del concepto del amor romántico y la firme resistencia de las mujeres a ocupar posiciones de inferioridad social y sexual con respecto al hombre"- esta forma de comedia "se ha convertido en foro de algunos de los debates más importantes sobre las relaciones entre los sexos y sobre las identidades masculina y femenina." (Deleyto, "Introducción” 117-118). Naturalmente no puedo entrar aquí en detalles de los derroteros seguidos a lo largo del tiempo por la comedia romántica cinematográfica. Valga decir que en los años 70 encontramos ejemplos notables, como Annie Hall y Manhattan de Woody Allen (1977), en los que se ha puesto en entredicho la confianza irrestricta en el amor romántico. En ambas películas, los personajes sienten la necesidad de buscarse a sí mismos; y a pesar de que perciben con ironía el ideal romántico, intentan construir una relación amorosa estable. Las dos terminan con la separación de los amantes.

Por lo que respecta a las películas de este género de los últimos años, es preciso señalar que acusan una notable falta de méritos artísticos; a pesar de lo cual, no se puede dudar de su permanencia en el cine hollywoodense. Ya en décadas recientes, Pablo Echart identifica dos vertientes claramente diferenciadas: por un lado, la grosera, en la que se observa un "sensible incremento de los gags 
escatológicos, la rudeza en los diálogos y la explicitud en el tratamiento de la sexualidad (más en el plano de las alusiones que en el de su representación), sin menoscabar por ello las convenciones más tradicionales e idealistas del amor romántico"; y por otro lado, la llamada comedia "retro" o "neotradicional", en la que se narran fantasías inocentes y amables —a veces hasta extremos insólitosla mayor parte de las veces de forma rutinaria y poco creativa ("La última comedia" 166-167).

Ahora bien, tras esta brevísima recapitulación a propósito de la comedia romántica, es momento de regresar a mi punto de partida, es decir, a las primeras preguntas sobre el género dramático de Testosterona y a mi propuesta de desentrañar los sentidos que se forjan con los cambios que se le imprimen al género. Pero vayamos poco a poco.

La acción de la obra comienza la tarde de un 24 de diciembre en un lujoso edificio, concretamente en "La oficina del último piso de un rascacielos, de una elegancia minimalista” (107). Se trata de la oficina de Antonio, el director de un periódico importante. Afuera llueve y "se escucha, de muy lejos, un jingle de Navidad" (109). La trama se desarrolla, como en muchas comedias románticas cinematográficas, en una gran urbe. ${ }^{8} \mathrm{Al}$ comenzar la obra la situación es sencilla: Antonio está a punto de irse al aeropuerto para viajar — en su avión particular-y llegar a casa, para pasar la nochebuena con su familia. Pero antes de hacerlo debe plantearle a Miky, la Subdirectora de Contenidos del periódico —Alex en la versión de 2017- una situación de gran trascendencia; se trata de un "gana todo o pierde todo" (113):

${ }^{8}$ Así ocurre en el filme británico Love Actually (2003), cuya acción se desarrolla en Londres, en los días previos a la Navidad. En esta película, protagonizada por un elenco de famosos actores, se narran una serie de historias divertidas, que nos hacen ver que el amor se puede encontrar en todas partes. De igual manera, Annie Hall y Manhattan, las dos célebres comedias románticas de los años setenta de Woody Allen, que marcaron un hito en la historia de este género cinematográfico, se desarrollan en espacios reconocibles de la isla de Manhattan, particularmente en los barrios elegantes de las clases acomodadas, como el Upper East Side y el Upper West Side, aledaños al Central Park. 
Antonio deja la dirección del periódico y debe elegir a su sucesor. Para ello considerará a dos candidatos. Elegirá de entre ellos “al líder más fuerte”, mientras que el otro será despedido — de este modo se despeja el camino para que el nuevo director seleccione a su propio equipo (126-127)—. Pero antes de llegar a este planteamiento, lo que ocurre cerca del final del primer acto, la escena nos ofrece datos importantes sobre los personajes y sus relaciones, que es necesario considerar.

Como corresponde a los protagonistas de una comedia romántica, tanto Antonio como Miky — los únicos que aparecen en escena- son personajes encantadores. Él "está en su cincuentena, tiene una melena blanca, un vigory una apostura que llenan el espacio" (109). Ella "tiene cuarenta y dos años, es atlética, va en traje de pantalón y saco . . no es una belleza, pero le tiene sin cuidado y se comporta como si fuera dueña del mundo" (109). Ambos pertenecen a una elite intelectual, moderna y atractiva, que puede aludir con soltura lo mismo a García Lorca que a los ideales libertarios del teórico de la contracultura Herbert Marcuse, o a Lévi-Strauss, y desde luego, como parte de la convención del género, a películas clásicas de los años cuarenta. Pertenecen a una sociedad urbana, en un mundo híper tecnologizado y gozan de un nivel económico que los orilla a "no ser dueños de su tiempo" (110). Han trabajado juntos por veinte años, aunque fue Antonio quien formó a Miky en el periodismo — se conocieron en la universidad donde ella estudiaba filosofía-; y a pesar de la relación jerárquica que existe entre ambos, su relación tiene un tono amistoso, en la que hay espacio para el juego.

Miky es un personaje que representa a la mujer moderna que vive con libertad su sexualidad y para quien existen más opciones que las relaciones heterosexuales. Para ella, amor y sexo son independientes; el erotismo no está necesariamente condicionado por el amor, por lo que puede constituir un fin en sí mismo. Tener una pareja no es un objetivo prioritario, ni su máxima aspiración en la vida, como sí ocurre en la mayor parte de las comedias románticas conservadoras; aunque, como señala Deleyto, hay comedias en las que los personajes son capaces de sentirse simultáneamente seducidos por la fantasía del amor romántico y al mismo tiempo distan- 
ciarse irónicamente respecto de las convenciones que dicha fantasía supone ("Amor, parodia y tiramisú" 129-130).

En la relación que ambos personajes establecen, ella ha sido la alumna destacada, que ha admirado a su maestro por años; mientras que él ha asumido actitudes hasta cierto punto paternalistas; con todo es claro que existe entre ambos una intensa atracción física que han logrado mantener bajo control, por lo que se han mantenido en los linderos del enamoramiento platónico. En el siguiente diálogo vemos cómo la situación excepcional en la que se encuentran posibilita que los dos personajes se confiesen lo que han sentido el uno por el otro, tras veinte años de silencio. La escena que evocan se remonta al tiempo en que se conocieron, cuando Antonio impartía un curso de periodismo en la universidad. Ella se sintió deslumbrada por el "reportero de las revueltas de estudiantes en París y Latinoamérica. El corresponsal de las guerras de Asia” (120):

Miky: Me sentaba a admirarte de lejos tomar tu café exprés, cortado, lo revolvías con una cucharita — eso me admiraba al extremo: tus dedos grandes, tus dedos machos, meneando la cucharita, en la tacita. No era posible que hubiera hombres así: tú con tu cigarro negro en la otra mano, tu chaqueta caqui de corresponsal, tu cabellera rubia de león, meneando la cucharita...

Antonio: Una tarde te apareciste a mi lado en el cine.

Miky: Dios. Me había olvidado de mi asalto al cineclub.

Antonio: ¿Cómo? Fue el día que lo nuestro se volvió importante. Estaban volviendo a pasar Casablanca.

MikY: Oh sí. ¿Qué pensaste?

Antonio: Pensé que. Que estaba casado, con un hijo recién nacido, y que era una lástima que los mundos paralelos no sean accesibles a voluntad.

Miky: Estás siendo amable. Pensaste: alerta roja, esta joven puede ser una psicótica.

Los dos se miran con atención. 
Antonio: No creo, porque empecé a murmurar los parlamentos medio segundo antes - para impresionarte. Mıky: Increíble: te sabías de memoria Casablanca. (120-121)

A estos parlamentos los siguen otros en los que ambos juegan recreando algunos momentos de la famosa película de 1942, hasta llegar a una de las frases con la que más se la asocia y una de las más memorables en la historia del cine: "Play it, Sam... For old times sake, play it Sam". Se trata, como todos recordamos, de la escena en que Ingrid Bergman, interpretando el personaje de Ilsa, le pide al pianista, Sam, que interprete una canción, no para recordar el pasado, sino para hacer como si el tiempo no hubiera transcurrido y los protagonistas del filme pudieran instalarse en "el instante infinito del enamoramiento", un instante que "vale por toda una eternidad" (Arias 51). Acto seguido, Antonio y Miky canturrean "As Time Goes By", mientras ella lo mira arrobada. Poco a poco evocan el tiempo en que comenzó su amistad y su relación profesional. Él la formó en el periodismo, ella fue un poco de barro entre sus manos, le dio la vida que tiene.

Como vemos, tal como ocurre en la realidad extratextual, en la ficción creada por Berman, el cine influye decisivamente en la manera como los personajes conciben el amor romántico. Llama la atención la alusión explícita a Casablanca - lo que ocurre en más de una ocasión a lo largo de la obra de Berman-, por varias razones.? En primer lugar, porque tal como señala García Mainar, en las llamadas new romances - es decir las comedias románticas de finales de los ochenta y principios de los noventa - son frecuentes tanto las referencias a las comedias clásicas cinematográficas, como la alu-

9 Si bien Casablanca (1942) no es exclusivamente una película romántica, ya que se pueden reconocer en ella dos líneas argumentales que se entrecruzan, una intriga política que sucede durante la Segunda Guerra Mundial y una historia de amor desgraciado entre Rick (Humphrey Bogart) e Ilsa (Ingrid Bergman), la película desarrolla uno de los conflictos amorosos por excelencia. Me refiero al triángulo amoroso, de gran presencia tanto en el arte cinematográfico como en teatral, ya sea en su vertiente seria o humorística. 
sión a ideas o motivos artísticos del pasado. Así, por ejemplo, muchas de estas comedias hacen referencia a narraciones románticas famosas. ${ }^{10}$ En segundo lugar, porque la evocación de filmes románticos que han marcado un hito en la producción cinematográfica, como es el caso de Casablanca, evidencia el reconocimiento, por parte de los personajes de Testosterona, de las convenciones y rituales del amor romántico. Lo cual no excluye que Miky y Antonio sean conscientes de la artificiosidad de sus códigos de seducción, de su naturaleza fantasiosa e idealizada. En otras palabras, ambos pactan para que el juego fluya. Así describe el fenómeno Celestino Deleyto en un artículo dedicado a la comedia romántica contemporánea, particularmente al filme Sleepless in Seatlle (1993), de Nora Ephron:

ni personajes ni espectadores creen en el amor 'que nos han vendido' pero, aun siendo perfectamente conscientes de que tal amor nunca ha existido en la realidad (ni en la realidad del espectador ni en la "realidad" ficticia de los personajes de las películas contemporáneas), quisieran creer que es verdad, que a ellos también les puede ocurrir. Es por eso por lo que son personajes de una comedia romántica y es por eso también por lo que los espectadores van a ver la película. ("Amor, parodia y tiramisú" 128)

Pareciera, pues, que Sabina Berman juega con una convención propia de las comedias románticas conservadoras — aunque los valores que se enarbolan en Testosterona sean muy diferentes de los que promovían dichas comedias-. A la vez se vuelve una manera eficaz de hacernos sentir a los lectores/espectadores que, pese a que Antonio y Miky viven en una época que ha buscado distanciarse de los paradigmas del amor convencional, de alguna manera sienten nostalgia

${ }^{10}$ Así ocurre, por ejemplo, en Hechizo de luna (Norman Jewison 1987), donde se alude a La Bohème; en Roxanne (Fred Schepisi 1987), a Cyrano de Bergerac; en Cuando Harry conoció a Sally (Rob Reiner 1989), a Casablanca; y en Mujer bonita (Garry Marshall 1990), a la leyenda de la Cenicienta (Deleyto, "Amor parodia y tiramisú" 122). 
por la idea de un romance idealizado, que se encuentra muy lejos de su experiencia cotidiana. ${ }^{11}$

Durante el segundo acto, ${ }^{12}$ antes del intermedio, la escena va cobrando cada vez una mayor tensión dramática: ambos están solos en el piso más alto del edificio, Antonio no puede viajar, una tormenta de nieve lo impide, por lo que se ve obligado a pasar la Navidad fuera de casa; ambos beben champaña y por momentos se enfrascan en discusiones acaloradas. Él le hace saber a Miky cuál es la razón que lo obliga a dejar la dirección del periódico: tiene un cáncer avanzado por lo que le pide que lo ayude a escribir sus memorias, para darle batalla a la Muerte. Pero, sobre todo, la tensión sexual y el deseo que hay entre ellos se va apropiando poco a poco de la escena. Esto lo percibimos en un principio por una serie de insinuaciones juguetonas. Sin embargo, la tensión llega a un punto culminante cuando él decide que pasará la noche en la oficina, donde ambos están solos. Tras unos silencios de indecisión ella se despide, para regresar unos instantes después:

MiKY: [tras un silencio] Me vi luchando contra la nieve para alejarme de lo que deseo. Así que di media vuelta, subí en elevador veintiocho pisos y estoy acá —donde está lo que deseo. No se mueven.

Ella se acerca más a él. Le quita los lentes...

Le abre el abrigo y pasa por abajo del abrigo las manos para abrazarlo. Él pasa las manos bajo el abrigo de ella.

11 "En los años 90 del siglo pasado se produjo un auge de la comedia romántica en detrimento del drama romántico. La fortaleza de la comedia romántica, que se mantiene en los comienzos del nuevo siglo, indica que la sociedad confía aún en el ideal del amor pese a vivir en la 'edad del descreimiento"', afirma Pablo Echart ("La última comedia" 186).

${ }^{12}$ La obra está dividida en tres partes o actos, sin embargo, entre el primero y el segundo no hay ninguna marca textual que indique una suspensión de la acción. En cambio, entre el segundo y el tercer acto hay una elipsis, un salto en el tiempo; así se indica en la acotación que abre la tercera parte: "El mediodía del día siguiente"; es decir que la acción se suspende la noche del 24 de diciembre y continúa hacia las 12 horas del día 25. 
El acto acaba cuando los personajes comienzan a hacer el amor. En ese momento las acotaciones indican que se hace un oscuro, al tiempo en que, poco a poco, se va encendiendo la luz de la sala, mientras se oye nuevamente la canción "As Time Goes By" (158). Las estrofas que se escuchan crean un ambiente de ilusión románti$\mathrm{ca}$, en la que el amor parece ser una fuerza inextinguible:

\author{
Moonlight and love songs, \\ Never out of date. \\ Hearts full of passion \\ Jealousy and hate. \\ Woman needs man \\ And man must have his mate. \\ That no one can deny. \\ It's still the same old story \\ A fight for love and glory \\ A case of do or die \\ The world will always welcome lovers \\ As time goes by.
}

Desde mi punto de vista, la manera en que se cierra el acto genera la expectativa en el lector/espectador de que Miky y Antonio puedan superar todos los obstáculos y terminar juntos. La experiencia como espectadores de comedias románticas nos dice que así ocurre en innumerables comedias, en cuyas tramas se construyen las condiciones necesarias para que la unión de la pareja sea posible, a pesar de que sus protagonistas tengan, en principio, concepciones de la vida radicalmente opuestas.

Como vimos al principio, las diferencias entre hombres y mujeres constituyen uno de los temas más socorridos en la comedia romántica, y en muchas ocasiones son la causa de las discrepantes visiones de mundo de las parejas cómicas. En Testosterona, Sabina Berman las evidencia poniendo en escena situaciones socialmente reconocibles, donde las diferencias jerárquicas entre los sexos determinan las conductas de los personajes. Así, por ejemplo, al co- 
mienzo de la obra Miky aparece cargada con los regalos de Navidad que ha comprado para su jefe.

Antonio: Gracias, Miky.

MikY: ¿De qué?

Miky empieza a acomodar los regalos en la mesa baja de la sala.

...

ANTONIO: ¿Qué haría sin ti?

Miky: Enviarías a tu secretaria.

Antonio: No tiene tu buen gusto. Cada año vuelve a pasarme, llega la noche del 24 de diciembre y yo estoy en la oficina, atendiendo los últimos impostergables.

...

MIKY: ¿De qué sirve una subdirectora de Contenidos si no es para comprar los regalos de la familia de su jefe? (110-111)

Como vemos, Miky "actúa” con naturalidad, aunque no sin un dejo de sarcasmo, el rol femenino que le "corresponde". Pero un poco más adelante, sobre todo a partir de que Antonio le pide a la subdirectora que le hable de su vida personal, pues lo considera necesario para la propuesta que le hará, los roles de género se vuelven un tema sobre el que discuten de manera explícita.

$\mathrm{Al}$ intentar responder a la pregunta sobre su vida privada, Miky reconoce que no hay mucho qué decir; su vida personal es casi inexistente, una "caja vacía". Su antiguo novio se esfumó porque ella no quiso tener una existencia más hogareña. "El novio", como ella lo llama, "sentía el tic-tac de su reloj biológico" (116) y no solo deseaba que pasaran juntos los fines de semana, sino que sentía una necesidad urgente de "reproducirse". Llama la atención cómo Miky retoma el lugar común del supuesto reloj biológico de las mujeres para mofarse de su exnovio. El tono burlesco continúa cuando además afirma que a él "no le bastaban los espejos" para reproducirse, por lo que, como era biólogo, se fue al Golfo de México "a reproducir pulpos" (116-117). Lo que me parece más interesante de este juego no es solo la inversión de roles que se da en la pareja, sino que resulta una forma jocosa de poner en cuestión una serie de ideas sobre 
las supuestas necesidades de las mujeres, ideas que en el espacio social se tienen casi por axiomas.

Sin embargo, unas líneas después vemos que la elección de Miky no es tan sencilla. No solo lleva la cuenta exacta del tiempo que ha transcurrido desde la partida de su ex — "cuatro meses y siete días" — sino que todavía al hablar del asunto se le cierra la garganta (117). Afirma también que "sus semanas son un largo día de trabajo lleno de gente, con pausas para dormir"; los domingos son "desiertos interminables", aunque la noche de los sábados tenga "sexo casual" (118). Pero sobre todo deja ver que en el mundo en que vive la maternidad no es una opción para la subdirectora de un periódico de gran calibre, si es que quiere vivirla plenamente:

Miky: Parir un hijo para luego delegar en fuentes externas su crianza me parece una pendejada. ... Yo quiero darle de mamar un año completo. Dormirlo abrazado a mi cuello, como un chango bonobo. Cargarlo como marsupial sobre la panza un par de años. Todo el paquete mamífero. Es decir, cuando lo tenga, o la tenga, si lo tengo, o la tengo. (119)

Por lo tanto, tener un hijo no queda excluido de la vida de Miky por su propio deseo sino por las condiciones laborales que debe cumplir si quiere desarrollar una carrera profesional de alto nivel. Desde luego, no es el caso de Antonio:

Antonio: Yo tengo cuatro hijos preciosos — dos de mi primer matrimonio, las gemelas del actual - y un nieto; pero soy hombre. Se sobreentiende que los cuidan las madres. Sus madres y las niñeras. Mi única obligación es disfrutarlos los domingos. Es injusto que. Es decir, es injusto que el mundo laboral siga siendo un mundo diseñado para hombres y por hombres. (118) 
$Y$ es precisamente en el universo laboral, ${ }^{13}$ pero con todas sus implicaciones en la vida privada, donde en la obra se muestran estas diferencias. Todo ello nos acerca a un debate ideológico que está presente en la sociedad actual.

En síntesis, durante los primeros dos actos, la pugna entre los sexos se establece en buena medida como una esgrima de ingenios, que debaten puntos de vista convencionales sobre la masculinidad y la feminidad, en la cual se ponen en circulación discursos críticos y hasta amargos sobre el matrimonio y las relaciones de pareja. Así y todo, no hay que perder de vista que en las comedias románticas es muy habitual que el amor se exprese en forma de hostilidad, hasta el punto en que, como afirma Echart, "distintas formas de agresión mutua, de supuesta aversión y enemistad se traban en una estructura narrativa que camina, sin embargo, hacia la unión/reunión de la pareja” ( $L a$ comedia 227).

Aunque por momentos el tono se vuelve confesional —lo que facilita la identificación del lector/espectador con los conflictos de los personajes_- hay constantes rupturas marcadas por un juego con el lenguaje que, sobre todo en Miky, suele ser sarcástico e irónico. A pesar de todo, hasta el fin del segundo acto la comedia parece cubrir a los personajes con su halo protector, lo que nos invita a considerarlos con cierta ligereza y esperar con optimismo un feliz desenlace. Esto cambia radicalmente en el acto tercero. La acción se retoma al "mediodía del día siguiente" (159). Antonio ha recibido ya las propuestas de Miky para la dirección del periódico y se ha entrevistado con Beteta para discutir las suyas. Las ideas de ella son "Brillantes. Audaces", va "engarzada al Espíritu del Tiempo" pero camina "dos pasos adelante" (161). Sin embargo, a pesar de todos

${ }^{13}$ En diversas entrevistas televisivas, Sabina Berman ha dicho que con Testosterona buscaba hacer una Casa de muñecas del siglo XXI, ya que, si en la obra de Ibsen la discusión sobre los derechos de las mujeres se daba en el ámbito familiar, en la intimidad de la casa, ahora, en el contexto del movimiento feminista actual, que en buena medida tiene como detonante el Mee too, la discusión se centra mucho más en los espacios de trabajo. 
sus méritos, Antonio decide que será Beteta, a quien ambos consideran un enano mental, el nuevo director.

Ahora es momento de detenerse a considerar las diferencias en la manera de trabajar de Miky y Beteta. Importan para la discusión que se entabla en la obra acerca de las actitudes "femeninas" y "masculinas". Mientras que él asume una actitud dictatorial con sus subordinados y es capaz de cualquier cosa, incluso de actos ilegales, para ganar una noticia, ella es una "jefa inspiradora", creativa, que sabe colaborar, escuchar a los otros y crear "sinergias horizontales". Con todo, a los ojos de Beteta y del propio Antonio, ella se comporta como "la madre Teresa de Calcuta" y, en resumen, le falta testosterona. Es decir, le falta ser competitiva, incluso al precio de ser injusta y no reconocer la idea de un subalterno; debe olvidarse de su don "para la horizontalidad" y aspirar a "ocupar la cima de la verticalidad" (132):

Antonio: El poder es vertical en el mundo como es, mi pequeña filósofa. En otros mundos posibles podría no serlo; pero en este mundo, lo es. Donde el poder es parejo hay fricción e inestabilidad, donde es vertical no hay fricción. (133)

Como vemos, Berman parece dar por bueno el lugar común que dice cuáles son las características "femeninas" y cuáles las "masculinas". Y no hay seña alguna en el texto, pensado en su conjunto, que sugiera, incluso pálidamente, que las relaciones laborales puedan ser de otro modo. La salida que tiene Miky es aumentar su agresividad y para ello debe tener más testosterona. "Te necesito con más pelotas", le dice Antonio al tiempo que le entrega, al final del primer acto, un sobrecito con la hormona, que ella se unta en el abdomen (134).

La noticia da un giro de 180 grados a las expectativas generadas tanto en Miky como en los lectores/espectadores, y da lugar a un cambio radical en el tono de la escena: los diálogos se vuelven agrios, pierden el ingenio para volverse agresiones directas, burdas, incluso soeces. Tras una serie de suposiciones, por parte de Miky, acerca de las razones que llevan a Antonio a tomar esa decisión, él le confiesa que se ve forzado. Beteta ha puesto cámaras en la 
dirección y los ha grabado durante la noche. Tiene fotos de ambos manteniendo relaciones sexuales y amenaza con denunciarlos ante la Junta que gobierna el periódico.

A partir de este momento Antonio se ve como un ser disminuido, mezquino, que solo busca encontrar una salida para salvarse a sí mismo, "una salida digna para este desastre" (174). "Ahora ya no se trata de. De ser felices. Se trata ya solo de salvar los despojos, las apariencias", afirma (177). La solución es que Miky se case con él y, desde luego, pierda su oportunidad de dirigir el periódico. Llega incluso a abofetearla porque en cierta forma la responsabiliza de la catástrofe:

Antonio: . . . Ahora estoy en manos de un inmoral, de un tipo sin remordimientos. ¡Estoy completamente en su poder! Y ese miserable me puede pedir lo que se le antoje, exigirme cualquier cosa sin que yo me atreva a protestar. ¿'Te alcanza el cerebro para comprender lo que me hiciste?

Miky: Sí.

Antonio: Qué bueno, porque a mí sigue pareciéndome imposible. Voy a apresurar el procedimiento. Ahora mismo, en unos minutos, voy a escribirle al Consejo mi decisión y pedirles que apresuremos las etapas. (176)

Pero antes de que se lleve a cabo el proceso de sustitución del director, Miky lo amenaza con denunciarlo por acoso sexual y narra lo ocurrido entre ambos durante esa noche, pero dándole un giro para que todo cuadre con la perspectiva del abuso. "Yo... regreso. Cedo por fin al acoso. Me entrego al acosador. Me jalas al escritorio. Se llama violencia física. Me penetras. Se llama violación" (180). Las mismas fotos tomadas por Beteta serán la prueba de lo que está dispuesta a afirmar. Ella misma redacta su nombramiento en la computadora de Antonio, lo sube a la red para que aparezca en la primera plana de la edición digital y lo envía al Consejo.

Durante los últimos diálogos, Miky va consiguiendo el aplomo y la fuerza que tanto admiraba en Antonio. La noticia se ha divulgado y los teléfonos no dejan de sonar. La última llamada que recibe es del propio Beteta, aunque la escuchamos solo a ella. Y lo que 
dice es prácticamente lo mismo que, unas escenas antes, le había dicho Antonio a ella:

MikY: . . Dije: cierra el puto hocico y escucha tú cómo será. Hoy no. El lunes. Cuando los empleados de Información te acompañen mientras vacías tu escritorio. Entonces bajaré a darte yo la despedida. Tú y yo nos daremos la mano. Nos tomarán algunas fotos. Le darás la mano al hijo de puta, que ahí estará también. Nos daremos todos las manos. .. . (185)

Finalmente, Miky —o Magdalena, como exige ahora que Antonio la llame ${ }^{14}$ - reproduce el estilo, los tonos de un jefe, asume el control, la "verticalidad". Y en este punto, me surgen dos preguntas: ¿Qué pasó con la comedia romántica?, ¿fue abandonada del todo? Dije arriba que el tono cambia por completo en el último acto. Ciertamente deja de ser ligero, para volverse agresivo, sin más. En esta medida hay una ruptura total con las convenciones genéricas. Queda por pensar en el "final feliz" que, aunque desaparece en algunos casos, se sigue asociando con la comedia. Desde una perspectiva conservadora, si pensamos en la posibilidad de la pareja, el desenlace no es afortunado. Pero hacerlo así supondría traicionar la preocupación central de la obra de Berman. El debate ideológico en que se centra Testosterona tiene que ver con los discursos sociales sobre los derechos de las mujeres, sobre el abuso y la violencia contra ellas; debate vigente en el espacio social contemporáneo, tan ajeno a la igualdad entre los sexos, y en el que están presentes las ideas dominantes sobre la masculinidad y la feminidad, sobre el amor y el sexo.

${ }^{14}$ Desde luego no es indiferente usar un nombre u otro. Los nombres con los que se nos llama no son nunca neutros. Por el contrario, se relacionan directamente con un contexto (tanto objetivo como subjetivo) en el que se dan las relaciones humanas y, por lo tanto, tienen que ver con las relaciones jerárquicas y de poder. Este simple acto del habla puede situar a los seres humanos en un lugar de dependencia o inferioridad. Por esta misma razón resulta develador, que Miky, unas líneas adelante, llame Tony a Antonio. 
Miky, como muchos personajes femeninos en las comedias románticas de Woody Allen, se ha sentido atraída por la mente brillante y la personalidad seductora de su antiguo profesor, pero ha terminado por darse cuenta de la opresión patriarcal en la que vive. Así, la obra construye una situación límite, pero no da lugar a una solución utópica, ni a la transformación cómica de los personajes. Las expectativas generadas hacia el final del segundo acto quedan completamente fuera de la obra y atestiguamos una disminución tajante en la presencia del humor. En este universo ficcional, el amor y el deseo no son la solución a los problemas.

¿Qué ocurre, entonces, si el final no es el final feliz de la comedia romántica? Hay que recordar que la comedia romántica no siempre celebra el matrimonio, aunque no cabe duda de que reflexiona sobre él; amén de que en los últimos tiempos han aumentado de manera considerable las dudas sobre la viabilidad del matrimonio en los filmes pertenecientes a este género (Deleyto, Woody Allen y el espacio 75). De esta manera quizá pudiéramos convenir que en Testosterona no se defiende o idealiza ni el amor ni la pareja, pero se reflexiona, así sea de manera tangencial, sobre ambos. Sin embargo, la obra va más allá. Las ideas sobre las conductas "femeninas" y "masculinas" reclaman la atención del lector/espectador.

Estamos ante un texto dramático que no se atiene hasta el final al género aludido. Que si bien en la primera parte, antes del intermedio, la autora juega con rasgos importantes de comedia, estos prácticamente desaparecen tras el intermedio. Con esto establece un camino para pensar en una realidad compleja, para cuestionar el discurso patriarcal, las ideas hegemónicas sobre los roles de género y la identidad sexual estereotipada. En esa medida se trata de una obra contestataria — como muchas otras de Sabina Bermanque pone en entredicho, que intenta desmitificar las estrategias del poder, dejándolas a la vista. El problema, en mi opinión, es que a final de cuentas, la única salida que tiene el personaje femenino es reproducir las estrategias masculinas de dominación y de ejercicio del poder. Resulta muy revelador que la propia Miky descubra qué es lo que la atraía de Antonio: 
MiKY: ¿'Te has preguntado por qué me quedé contigo ayer? Antonio: Me dijiste que me has deseado durante años. Miky: Pero ¿por qué te he deseado? ¿Qué deseaba en ti? Antonio: Tú dime, Miky.

Miky: ¿'Tus piernas atléticas? ¿'Tu torso herculano? [sic] ¿'Tu rostro apolíneo, sin una raya de edad?

Antonio: Supongo que no.

Miky: Deseaba tu seguridad, tu aplomo, tu autoridad. Lo deseaba con todo mi deseo. Quería tocarlo, abrazarme a él, quedar incluida en su halo. Y chuparlo, lamerlo, tenerlo dentro de mí. Absorberlo. Y ayer, cuando lo pusiste a concurso, también deseaba tu puesto. Esta oficina. Tu escritorio. Tu chofer. Tu jet. Ser tú mismo. ¿Qué me das ahora a cambio? Algo que yo no deseo por mi cuenta. Un matrimonio con un pobre hombre enfermo. Un libro que yo podría escribir por mi cuenta. Un hijo que yo puedo tener por mi cuenta. (173)

En síntesis, el personaje femenino ha terminado por interiorizar las estrategias de ejercicio del poder. "[E]l sujeto se forma en la subordinación”, en palabras de Butler (13). Desde luego no quiero decir que la mujer no pueda o deba ejercer el poder. Reconozco también cómo en el espacio social se mide con dos raseros diferentes las actitudes determinadas y ambiciosas en los hombres y en las mujeres. En ellos es una virtud mientras que en las otras es un defecto. Asimismo, debo reconocer que me parece una pena que la obra abandone el sentido del humor como apuesta artística y que la "solución" a los conflictos de género sean las mismas actitudes que ha enarbolado una sociedad injusta, que exalta las cualidades supuestamente masculinas como la agresividad, la independencia y la dominancia, mientras que rechaza las cualidades supuestamente femeninas, como la sensibilidad y la solidaridad con el otro.

Por último, la obra se cierra con otra repetición, casi un déjà $v u$. Antonio ha abandonado la oficina, para regresar unos instantes después:

Entonces se abre la puerta. Es Antonio, que ha vuelto. Miky pone el auricular a un lado, descuelga el otro auriculary lo deja a un lado. Pulsa 
el mute del celular. Todo queda en silencio.

Antonio: Mi bufanda. La olvidé.

Miky: Ya.

Antonio va al perchero y toma su bufanda.

Antonio: Bien hecho.

Miky: ¿Perdón? No te escuché. Repítelo.

AnTONIO: Bien hecho.

Miky: Música para mis oídos. Repítelo.

Antonio: Bien hecho.

Miky: Siempre te he amado - y siempre te amaré.

Antonio la besa en los labios. Un beso largo. Luego camina a la salida.

Suena el teléfono.

Cuando Antonio sale ella responde el teléfono.

Miky: (Por fin con el aplomo de él.) Sí.

Oscuro. (186-187)

Como vemos, parece haber una concesión final al género de la comedia romántica. Es, me parece, un final más convencional que sustentado en el desarrollo del conflicto y de los personajes; un guiño que busca dejar en el lector/espectador un sabor de boca más dulce.

\section{Bibliografía}

A’ness, Francine M. "Diálogo con Sabina Berman”. Sediciosas seducciones: sexo, poder y palabras en el teatro de Sabina Berman, compilado por Jaqueline E. Bixler, Escenología, 2004, pp. 43-63.

Arias, Luis Martín. ““'Dios te bendiga!’: utopía y anamnesis en Casablanca". Trama y fondo: Revista de cultura, no. 18, 2005, pp. 31-54.

Berman, Sabina. "Testosterona". El narco negocia con Dios. Testosterona, prólogo de Stuart A. Day, El Milagro / CNCA / LATR Books, 2013, pp. 106-187.

Butler, Judith. Mecanismos psíquicos del poder. Teorías sobre la sujeción. Traducción de Jacqueline Cruz, Cátedra / Universidad de Valencia, 2015. 
Carbajosa, Natalia. e-book, Shakespeare y el lenguaje de la comedia. Teoría, crítica y análisis. Verbum, 2009.

Deleyto, Celestino. "Amor, parodia y tiramisú: Sleepless in Seattle y la comedia romántica contemporánea”. Archivos de la Filmoteca, no. 44, 2003, pp. 121-139.

. "Introducción". Dossier "La comedia romántica estadounidense en la década de los noventa", Archivos de la Filmoteca, no. 44, 2003, pp 116-119.

- Woody Allen y el espacio de la comedia romántica. Ediciones de la Filmoteca, 2009.

Echart, Pablo. La comedia romántica del Hollywood de los años 30 y 40. Cátedra, 2005.

. "La última comedia romántica estadounidense (2000-2007): panorámica de un género ensimismado". Comunicación y Sociedad, no. 1, 2009, 161-195.

Frye, Northrop. Anatomía de la crítica. Monte Ávila, 1991.

García Mainar, L. M. "El amor en la encrucijada: comedia romántica, identidad y autor en Manhatann Murder Mystery". Archivos de la Filmoteca, no. 44, 2003, pp. 173-191.

Singer, Irving. La naturaleza del amor. 2 Cortesano y romántico. Traducción de Victoria Schussheim. Siglo XXI, 1992. 